\title{
Investigating the Impact of External Factors on User Perceptions: A Case Study of Software Adoption in Middle East
}

\author{
Tahereh Monzavi $^{1}$ \\ Department of IT Management, School of Engineering, Alzahra Uvniversity, Tehran, Iran \\ Behrouz Zarei ${ }^{2}$ \\ Department of Corporate Entrepreneurship, University of Tehran, Tehran, Iran \\ Amir Hossein Ghapanchi ${ }^{3}$ \\ School of ICT, Griffith University, Queensland, Australia \\ E-mail: a.ghapanchi@griffith.edu.au
}

\begin{abstract}
This paper identifies a set of external factors which may influence on users' perceptions about an information system's ease of use and usefulness underlying user beliefs. The research model was developed based on Davis's Technology Acceptance Model (TAM) along with extending a comprehensive list of organizational, social, individual, and technological factors as the determinants of users' perceptions about a technology. The research model was tested through a quantitative analysis of a dataset collected from 128 users of Project Management Information System (PMIS), software for managing the flow of information across the entire company's projects. Partial Least Squares (PLS) supported the significant impact of the following factors on users' beliefs in terms of Perceived Usefulness: organizational factors including User involvement in system development and Communication channels, social factors including Subjective norms of peers and informal groups and technological factors include Task-Technology Fit; and Quality of relationship with managers and peers; individual factors including Self-efficacy and Personal innovativeness; and technological factors including Compatibility were the most important antecedent of the belief variable in term of Perceived Ease of Use. Finally, the research implications and future directions are discussed.
\end{abstract}

Keywords: Software adoption, user perception, belief antecedents, Partial Least Square (PLS).

\section{Introduction}

Information Technology (IT) has been increasingly adopted by various organizations of any sort. Information is important because it influences the performance of an organization, thus, it needs to be effectively and efficiently managed and controlled. Evidence shows that many organizations are still unable to gain the maximum benefits from the implementation of information technologies. One reason has been paying too much attention to the technological aspects of information system implementation and ignoring the psychological aspects of it and the key role that users play in the success of any information system. Implementing a new information system in an organization normally involves some changes to the normal operation of the organization. For the users it may mean a level of ambiguity and risk. Therefore, the users are likely to resist to the full adoption of the new information system, unless the consequences of the new information system and its specific benefits for the users are made clear to them.

User beliefs and perceptions are introduced as determinants of user behavior in Technology Acceptance Model (TAM) by Hauge et al. ${ }^{1}$ and Bajec ${ }^{2}$. This model, on the other hand, posits that there may be some external factors that impact users' perceptions and attitudes towards a new technology. A number of researchers have come up with various external factors that may impact user perceptions and 
attitudes. For example, Jackson et al. ${ }^{3}$ examined the impact of situational involvement, intrinsic involvement, prior use, and argument of change; Gefen and $\mathrm{Kail}^{4}$ examined the effect of the perceived developer responsiveness; Karahanna et al. ${ }^{5}$ investigated the influence of compatibility, trainability, visibility, and result demonstrability; and Davis et al. $^{6}$ examined the impact of computer selfefficacy, objective usability, and direct experience. Despite the attempts of such researchers, there is a lack of research that systematically lists and categorizes a relatively comprehensive list of external factors impacting user perception and attitudes towards an information system. Therefore, this research seeks to extend the previous works on the determinants of users' perceptions and beliefs about a technology by identifying and including a detailed list of organizational, social, individual, and technological factors. By finding the external factors that have significant impacts on users' perception and beliefs about an information system, this paper sheds lights on the understanding of user resistance to the new technology and helps managers select appropriate organizational strategies towards more desired outputs. This study aims to investigate the factors influencing user perceptions associated with technology adoption.

The paper is organized as follows. Next section provides a literature review of innovation as well as technology adoption and its drivers. The third section identifies four groups of factors that influence user perception and suggests an extended conceptual framework. A case study, sample and data analysis procedure are presented in the fourth section. The fifth section reflects data analysis and results. Finally, it discusses the results of the study.

\section{Literature review}

Understanding why people do not use information systems had always been faced with many challenges. The impact of users' internal beliefs and attitudes on their usage behavior have been studied by many researchers including DeSanctis ${ }^{7}$; Fuerst and
Cheney $^{8}$; Ginzberg 9 ; Ives et al. $^{10}$; Lucas $^{11}$; Robey ${ }^{12}$; Schultz and Slevin ${ }^{13}$; Srinivasan ${ }^{14}$ and Swanson ${ }^{15}$. On the other hand, these internal beliefs and attitudes are shaped by various external factors. Some of these external factors have been mentioned in the previous research for example, the system's technical design characteristics by Benbasat et al. ${ }^{16}$; Dickson et al. ${ }^{17}$ and Malone ${ }^{18}$; user involvement in system development by Baroudi et al. ${ }^{19}$; Franz and Robey ${ }^{20}$; the type of system development process by Alavi ${ }^{21}$; King and Rodriguez ${ }^{22}$; the nature of the implementation process by Ginzberg ${ }^{23}$; Vertinsky et al. $^{24}$; Zand and Sorensen ${ }^{25}$; and cognitive styles by Huber $^{26}$.

The importance of the person's attitude and beliefs has also been emphasized in the theory of Reasoned Action (TRA) by Fishbein and Ajzen27. According to this theory, which is originated from social psychology, a person's behavior is predicted by the intention to perform that behavior. In turn, intention is predicted by the person's attitude and subjective norm. Ajzen28 suggested Theory of planned behavior as an extension of TRA that considers behavioral control as an important factor in influencing user behavior toward acceptance of the new technology.

The innovation Diffusion Theory is the other famous theory in the information systems (IS) literature which was proposed by Rogers ${ }^{29}$. According to this theory, users' perception of a new system is an introduction to its acceptance. It also emphasizes the role of communication channels as a tool to facilitate innovation diffusion. Subject to this theory, users decide on accepting the new technology based on their perception of the five characteristics of the system: relative advantage, compatibility, complexity, trial ability and observability.

Technology acceptance model (TAM) is an extension of TRA which was proposed by Davis ${ }^{30}$ to apply only to computer usage behavior. According to TAM, user beliefs influence attitudes which in turn shape behavioral intentions and finally lead to actual system use as demonstrated in Figure 1. User beliefs consist of two key components: perceived usefulness and perceived ease of use.

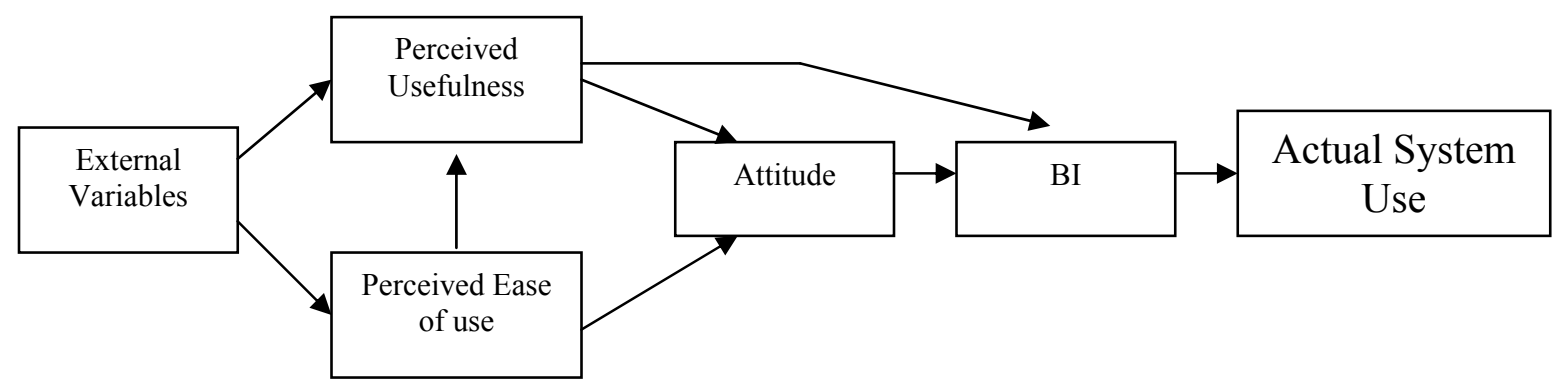

Fig. 1. Technology Acceptance Model (TAM) (Source: Davis et al. ${ }^{6}$ )

Published by Atlantis Press

Copyright: the authors 
According to Davis et al. ${ }^{6}$, Perceived usefulness (PU) is defined as the user's perception about the system usefulness which will enhance the job performance. Perceived ease of use (EOU) refers to the degree to which a user believes that the system usage would be free of effort.

In fact, perceived usefulness and perceived ease of use in TAM, are similar to two concepts of "Relative advantage" and "Complexity" in Innovation Diffusion Theory. In other aspect, IT is a tool for doing tasks better, therefore evaluating adaptation of a new system to an organization without considering user tasks would not be useful. Although the concept of "Usefulness" consists of user task implicitly, it is needed to consider user tasks explicitly. Then, TaskTechnology Fit model was introduced by Goodhue and Thompson ${ }^{31}$ to overcome this limitation. According to this model, factors such as user motivation, prior experience related to information systems and task characteristics determine user behavior toward system adaptation. Existing fit between technology characteristics such as software, hardware, network and user tasks influence adaptive behaviors. This coordination alignment will lead to supporting the new technology from user tasks and enable the users to accomplish their tasks. In spite of structural differentiation between these models, all of them emphasize the important role of user beliefs and perception toward using behavior.

\section{Developing the Research Model and Hypotheses}

In the face of a change, people first evaluate the situation and then their beliefs are shaped. In this process, a user may ask the question that "what are the benefits of this change for me?" This question determines the user's reaction to the change. Introducing a new technology to an organization is an important change. If users are aware of the advantages of the new technology and are able to see its benefits, resistance will be reduced considerably. Otherwise, negative perception and performance should be expected. Not surprisingly, a successful adoption of the new technology depends on the perception of the end users.

Researchers have mentioned user beliefs and perception as antecedents to accepting a new technology e.g. Agarwal and Prasad ${ }^{32}$; Venkatesh and Davis $^{33}$; Agarwal and Karahana ${ }^{34}$. Lewis et al. ${ }^{35}$ has mentioned that belief is considered as a mental concept which is formed by influencing from a wide range of external factors in the psychological literature. In the IS field, wide variety of information from different sources construct an individual's beliefs toward the technology use. Beliefs have significant impact on individual behaviors toward information technology. Thus, as Agarwal $^{36}$ has pointed it is worthy to understand how individual's beliefs about using a system is formed and what its antecedents are.

Although IT implementation seems to be related to the technological issues due to the visual characteristic of IT systems, it is essential to consider other factors namely organizational factors, social factors, and individual factors. According to Lewis et al. $^{35}$, all of these factors have potential impact on user beliefs by influencing two key perceptions about a new technology: perceived ease of use and perceived usefulness.

\subsection{Organizational factors influencing primary evaluation of user}

When looking at IT adoption, analyzing and studying users is important. Users are influenced by a variety of organizational factors. Therefore, these factors and their influence on the users' beliefs could be a major determinant of user behavior. Numerous studies have already been carried out on this subject e.g. LeonardBarton $^{37} ; \mathrm{Zmud}^{38}$ and Boynton et al. ${ }^{39}$ ). However, less attention is on presenting a holistic view on organizational factors, which include:

- Management commitment and support (TOPSUP: Top management support, MIDSUP: Middle management support): In this way, top and local management commitment and support influence user beliefs towards technology use. According to Eisenberger et $\mathrm{al}^{40}$, introducing a new technology brings ambiguity and risk, and top management commitment and support reduces negative reactions and create a positive feeling. Lewis et al. ${ }^{35}$ and LeonardBarton $^{37}$ have mentioned that feedback from management reinforces the users' perceptions about the new system. Local managers play an important role in reinforcing signals emanating from top management as well. It is expected that management commitment and support have positive impact on user beliefs about system usefulness and ease of use.

- Accessibility (ACCESS): It is expected that accessibility will be effective in forming beliefs about system ease of use. It consists of physical access to the computer systems and availability of the user training and support. Easy access to the new system and providing proper training programs influence user beliefs about system ease of use. 
- Reward-performance relationship (REW): Lucas $^{41}$ used the expectancy model which was introduced by Porter and Lowler ${ }^{42}$ to study problems in the implementation of information systems. Based on this model, user perceptions are formed concerning the value of rewards received from performance, the likelihood of rewards resulting from performance, and the likelihood of performance resulting from system use. Therefore, in order to form positive user beliefs, the new system should enhance the user performance and rewards. Then, it is expected that reward-performance relationship can influence user beliefs about system usefulness.

- User involvement in system development (INVOL): In view of the organizational behavior theories, employees' involvement leads to job satisfaction and performance improvement. According to Ives and Olson $^{43}$, user involvement in developing an information system is a special involvement in the organization. During the primary steps of developing an information system, user needs are not completely identified, but will become more apparent in the course of development. Thus, user involvement in system development would enhance system capabilities in doing task requirements and has positive influence on beliefs about ease of use and usefulness of the new system.

- Communication channels (CHANNEL): According to Nilakanta and Scamell ${ }^{44}$, information flows from one point to another in an organization through communication channels. Based on the Innovation Diffusion Theory, communication channels are responsible for improving user perceptions about a new technology. During the "innovation adoption", users obtain more information regarding the new technology which reduces ambiguity. Agarwal and Prasad $^{45}$ indicated that both general and specific information about the innovation were disseminated through the communication channels. Therefore, communication channels have positive influence on forming the user beliefs about ease of use and usefulness of a new technology.

Based on the studies cited above, we hypothesize that:
H1a: Management commitment and support have positive impact on user beliefs about system usefulness.

H1b: Management commitment and support have positive impact on user beliefs about system ease of use.

H2: Accessibility has positive impact on user beliefs about system ease of use.

H3: Reward-performance relationship has positive impact on user beliefs about system usefulness.

H4a: User involvement in system developing has positive impact on user beliefs about system usefulness.

H4b: User involvement in system developing has positive impact on user beliefs about system ease of use.

H5a: Communication channels have positive impact on user beliefs about system usefulness.

H5b: Communication channels have positive impact on user beliefs about system ease of use.

\subsection{Social factors influencing primary evaluation of user}

The role of social influence in behavioral adoption emanates from behavioral models in social psychology (TPB and TRA). Taylor and Todd ${ }^{46}$ and Thompson et al. ${ }^{47}$ introduced subjective norms as the antecedents of behavior. Factors of social influence include:

- Subjective Norms of Department peers (DEP $\mathrm{SN}$ ), and Informal Groups (INFORMAL $\mathrm{SN})$ : in the psychological research, the influence of the subjective norms on the behavioral intention is highlighted e.g. Bandura $^{48}$. People often shape their behavior basis with respect to the norms and group values. According to Ajzen and Fishben ${ }^{49}$, often evidence of others' behavior influences individual behavior and leads to the emergence of the same behavior. Empirical evidence shows the important role of this factor in emanating behavior accordingly e.g. Karahana and Strub $^{50}$; Matheison ${ }^{51}$; Lewis et al. ${ }^{35}$. Users gain satisfaction from the people who mind their own opinion (referent power). Furthermore, peers' opinions about system usage in the department and out of department could be important. Therefore, subjective norms of peers at the same department and from other departments have positive influence on the user beliefs in system usefulness. 
- Quality of Relationship with Managers and Peers (REL): In previous studies, Leadermember exchange (LMX) has been considered as a multidimensional concept which contains both formal reporting and the informal social exchange e.g. Dienesh and Liden $^{52}$; Sparrowe and $\operatorname{Liden}^{53}$. Also, influence of the quality of relationship in organization, including employee-manager relationship and relationship between employees, have been studied in previous researches for example Bolino et al. $^{54}$. According to Krackhardt ${ }^{55}$ and Leana and Van Buren $^{56}$, in an organizational context if individuals make a sense of convenience, information sharing about using the new technology would occur easily. Magni and Pennarola $^{57}$ argued that quality of organizational relationship increases team identification which facilitates the quality of information flows among members and finally leads to forming positive beliefs about the new technology. They found usefulness is positively related to the quality of the relationship between individuals and team leaders, and individuals and the organization; while, ease of use is positively influenced by user-organization and userteam relationships. Then, existence of a good LMX helps managers transfer benefits of the new system to employees easily. Thus, high quality of relationship with managers and peers influences users' beliefs about ease of use and usefulness of the new system.

Thus, we propose that:

H6: Subjective norms of department peers and informal groups have positive impact on user beliefs about system usefulness.

H7a: Quality of relationship with managers and peers has positive impact on user beliefs about system usefulness.

H7b: Quality of relationship with managers and peers has positive impact on user beliefs about system ease of use.

\subsection{Individual factors influencing primary evaluation of user}

Different people in the organization adopt the new technology with different paces; some adopt sooner and others later. This is due to the differences in individual characteristics, which can be categorized as follows:

- Self-efficacy (SELF): according to social cognitive theory by Bandura ${ }^{48}$, people have a self control power over their feelings and behaviors. Cognitive processes, emotional tendency, feelings and expectations play an important role in individual behavior. Computer self-efficacy (CSE), which is confidence in one's ability to use computer skills to execute a task, has been found to be a reliable determinant of acceptance intention and using behavior. Previous researches in the IT context highlight the importance of self-efficacy in user behavior toward a new system use e.g. Venkatesh and Davis ${ }^{33}$; Agarwal ${ }^{36}$; Hasan ${ }^{58}$; Lewis et $\mathrm{al}^{35}$. People with powerful beliefs regard to their abilities of doing new things, are more rigorous to adapt to the new technology. In other words, self-efficacy causes motivation and more perseverance. It is expected that individual with powerful self-efficacy has more potential to adapt to a new technology and form positive beliefs of ease of use and usefulness of the technology.

- Personal Innovativeness (INNO): Boyd and Mason $^{59}$ identified challenging goals, control center and ability of standing in ambiguous situations as major characteristics of innovative people. Agarwal and Prasad ${ }^{60}$ introduced individual desire to try new technologies as a sign of personal innovativeness. According to Rogers ${ }^{29}$, innovativeness plays an important role in diffusion and extension of positive beliefs among other users through communication channels. Lewis et al. $^{35}$ demonstrated that personal innovativeness can influence on the beliefs about technology usage. Thus, it is expected that personal innovativeness has positive influence on ease of use and usefulness beliefs in the new technology.

Based on these arguments, we test the following hypotheses:

H8a: Self-efficacy has positive impact on user beliefs about system usefulness.

H8b: Self-efficacy has positive impact on user beliefs about system ease of use.

H9a: Personal innovativeness has positive impact on user beliefs about system usefulness.

H9b: Personal innovativeness has positive impact on user beliefs about system ease of use. 


\subsection{Technological factors influencing primary evaluation of user}

- Task-Technology Fit (TTF): According to Dishaw and Strong $^{61}$, matching technological characteristics with user task requirements leads to more system using. The weakness of new technology in supporting user tasks is a threat. Whereas, the fit between task requirements and technological characteristics is an opportunity for users to improve their performance. Therefore it is expected that a good fit between technological characteristics and users' task requirements has a positive impact on user beliefs of usefulness of the new system.

- Essential Infrastructure (INFRAS): Based on Ross et al. ${ }^{62}$ research, during implementation of a new technology, it is required to invest in infrastructure such as computer hardware and software, network and communication facilities, shared databases and platforms. Integration of these items is important for successful implementation which will contribute to better system usage. Therefore, suitable infrastructure has positive influence on user beliefs about ease of use and usefulness of the new system.

- Compatibility (COMP): Moore and Benbasat ${ }^{63}$ indicate that information systems should be compatible with user needs, values and prior experiences, as well as existing systems to be accepted by users easily. Lack of system compatibility with other systems in organization, will create problems in intra-organizational relationships, and then it could have negative impact on user beliefs. System incompatibility with organizational values and users' prior experiences would create difficulties in doing tasks and reduce probability of adoption. Thus it can be proposed that compatibility has a positive influence on user beliefs towards ease of use and usefulness of the new system.

- Data Security (SEC): Policies and methods should be used to prevent unauthorized access to information. Data security control makes users feel assured toward information preservation. Using passwords while logging in and entering data to the system should be considered. Using firewalls while transmitting information through extranets and connecting to internet play a vital role in system security protection. Therefore, it is expected that data security has positive influence on user beliefs in usefulness of the new system.

This leads to the following hypotheses:

H10: Task-Technology Fit has positive impact on user beliefs about system usefulness.

H11a: Essential Infrastructure has positive impact on user beliefs about system usefulness.

H11b: Essential Infrastructure has positive impact on user beliefs about system ease of use.

H12a: Compatibility has positive impact on user beliefs about system usefulness.

H12b: Compatibility has positive impact on user beliefs about system ease of use.

H13: Data Security has positive impact on user beliefs about system usefulness.

Figure 2 shows the research model which is conceptually based on TAM by Davis ${ }^{30}$. This model emphasizes on individual beliefs as the main driver of behavior toward technology use. The role of belief in technology acceptance has been highlighted in the other previous works as well. Given the importance of beliefs, the research's focus is on external factors as the determinants of Perceived Usefulness and Perceived Ease of use underlying beliefs. 


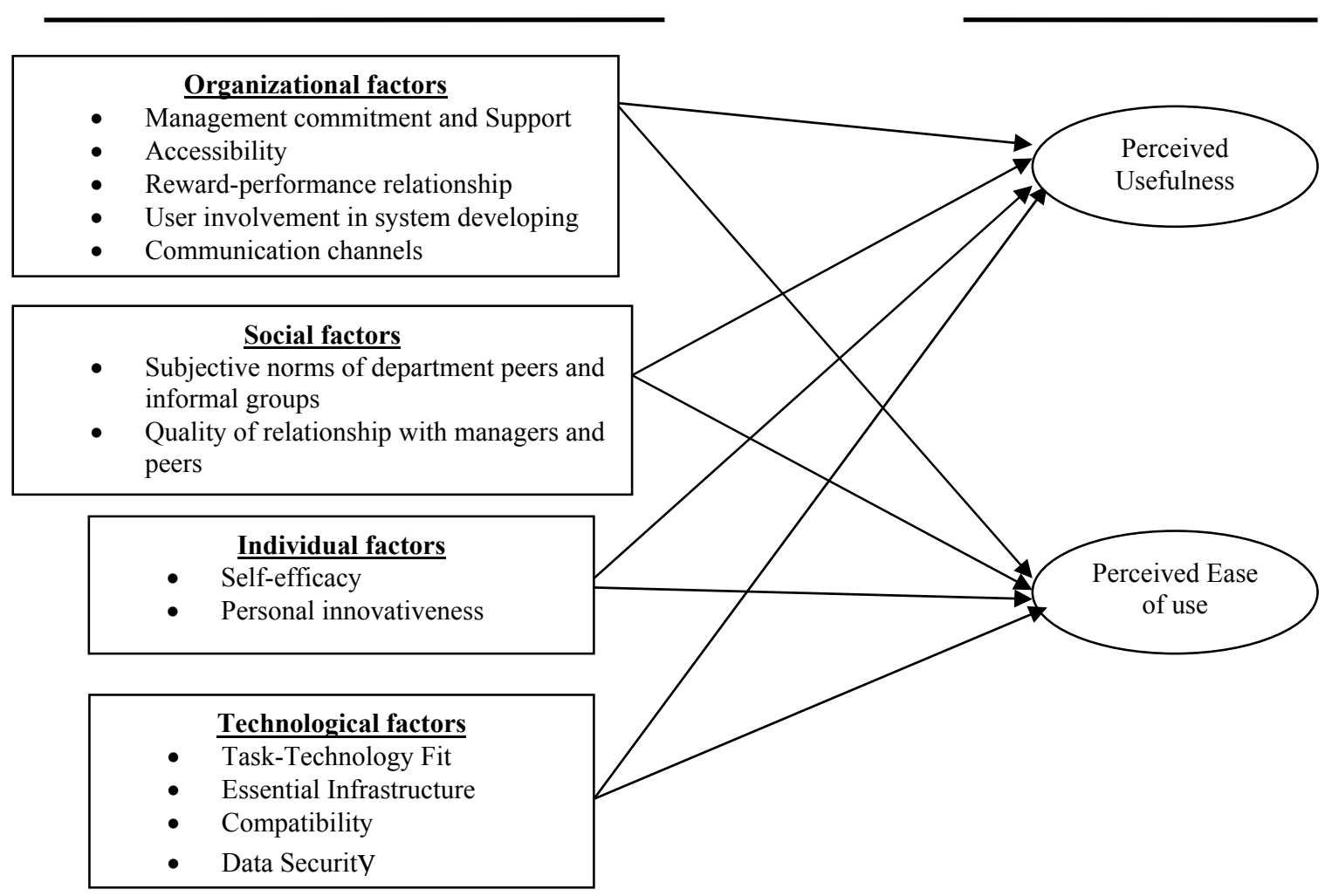

Fig. 2. Research model (source: developed for this study)

\section{Research Methodology}

In order to find which factors is the most important antecedent of the belief variable in term of Perceived Ease of Use and Perceived Usefulness, a questionnaire included a broad range of issues related to the external variables which influence on beliefs was designed. Participants responded using a fivepoint Likert scale representing a range from "1" (strongly agree) to "5" (strongly disagree). Table 1 lists the scales and questionnaire items. See Appendix 1 for all scales and items.

Table 1. Scales and questionnaire items

\begin{tabular}{ll}
\hline Scales & ITEMS \\
\hline TOP/MID SUP & $\begin{array}{l}\text { Committing to the vision of using the new system, Supporting and } \\
\text { encouraging users' efforts, Financial support, Emphasizing on the } \\
\text { system use. }\end{array}$ \\
Availability of trial version, help desk and training. \\
ACCESS & $\begin{array}{l}\text { Existence of a link between rewards and user performance, } \\
\text { appropriateness of rewards and performance improvement. }\end{array}$ \\
REW & $\begin{array}{l}\text { Providing feedback about the system functionalities, consideration of } \\
\text { users' ideas. } \\
\text { Receiving information from various channels, workshops, internal }\end{array}$
\end{tabular}




$\begin{array}{ll}\text { (DEP SN)/(INFORMAL SN) } & \begin{array}{l}\text { and external resources. } \\ \text { Opinion of colleagues and informal groups about the new system, } \\ \text { Importance of their opinions to users. } \\ \text { Quality of relationship between managers and employees, level of } \\ \text { REL }\end{array} \\ \begin{array}{l}\text { user commitment to the organization. } \\ \text { Ability to use the new system without any help, prior experience, ... }\end{array} \\ \text { INNO } & \begin{array}{l}\text { Being pioneer in adopting new technologies and learning new skills. } \\ \text { Appropriateness of hardware and software facilities, Subsystems }\end{array} \\ \text { INFRAS } & \begin{array}{l}\text { integration and frequency of downtimes. } \\ \text { System ability to provide required, up to date and detailed } \\ \text { information and high level of outputs to users, as well. }\end{array} \\ \text { TTF } & \begin{array}{l}\text { Level of consistency between the new system and users' work styles, } \\ \text { norms and values and current systems as well. }\end{array} \\ \text { COMP } & \text { Level of authorization access to data, security policies, .... } \\ \text { SEC } & \begin{array}{l}\text { Improving job performance and quality of the works by using the } \\ \text { new system. } \\ \text { PU }\end{array} \\ \text { Being easy to learn and use the new system for users. }\end{array}$

The questionnaire was sent to the users of software called Project Management Information System (PMIS) in Iranian Offshore Engineering Company (IOEC). This software manages the flow of information throughout the company and collects the information on transactions in an integrated data structure across the all projects.

In order to ensure data quality, the research instrument was pre-tested in the engineering department with 40 users. It was found that the instrument had a high reliability with a Cronbach alpha of 0.9. The final questionnaire along with a cover letter explaining the purpose of the study were sent to 160 users of the previously-mentioned information system.

A total of 128 users replied with no missing data, giving an effective response rate of $80 \%$. It took about three weeks to collect the data. Of the participants, $66 \%$ were males and $33 \%$ were females, $45 \%$ from engineering department, $35 \%$ from project control department, $15 \%$ from procurement department and 5\% from pipe coating department. Of these, $70.8 \%$ were between 15 and 35 years old, $24.4 \%$ were between 35 and 55 , and $4.7 \%$ were over 55 years of age.

In our sample, there was different organizational level: top management $12 \%$; middle management $40 \%$; technical staff $35 \%$ and the other staff $3 \%$.

To test the hypotheses of this study, Partial Least Squares (PLS) approach has been applied. According to Chin64, PLS uses a component-based approach to estimation that places minimal demands on sample size and residual distributions. Popularity of this approach within the research community has increased during the past few years because of its ability to model latent constructs under conditions of non-normality and small to medium sample sizes.

This study employed Partial Least Squares (PLS) for the data analysis because of its ability to handle reflective measures as well as its ability to predict the variability of the dependent construct. PLS was preferred over multiple regression analysis for two main reasons: (i) its ability to simultaneously estimate the interrelation between multiple dependent and independent variables, and (ii) its ability to support unobserved variables (latent constructs). The PLS method has been frequently employed by researchers in recent years.

\section{Results and Discussion}

Smart PLS (version 2.0.M3) were used for our data analysis. Based on the suggestion of Cotterman and Senn $^{65}$, bootstrap re-sampling procedure with 200 samples was also employed to test the significance of all paths.

Table 2 presents the results of PLS analysis for the research model. Path coefficient and t-values (within brackets) for each relationship are shown in this table. In the following paragraphs, the results of hypothesis testing will be demonstrated. For ease of exposition, description of path coefficient and t-values has been given only for significant relationships. 
Table 2. The results of PLS analysis: path coefficients and t-values

\begin{tabular}{|c|c|c|}
\hline Dependent variables $\square$ & Perceived Usefulness & Perceived Ease of use \\
\hline Predictors $\boldsymbol{\nabla}$ & Coefficient (t-value) & Coefficient (t-value) \\
\hline H1: Management commitment & $0.032(0.300)$ & $0.212(1.783)$ \\
\hline H2: Accessibility & $-0.125(1.162)$ & $0.039(0.313)$ \\
\hline H3:Reward-performance relationship & $0.007(0.081)$ & $0.009(0.092)$ \\
\hline H4:User involvement in system developing & $0.233^{* *}(2.586)$ & $0.084(0.868)$ \\
\hline H5:Communication channels & $0.054 * *(3.072)$ & $-0.172(1.300)$ \\
\hline H6:Subjective norms of department peers and informal groups & $0.262 * *(2.759)$ & $-0.074(0.711)$ \\
\hline H7:Quality of relationship with managers and peers & $0.017(0.172)$ & $0.302 * *(3.072)$ \\
\hline H8:Self-efficacy & $0.078(0.888)$ & $0.210 *(2.309)$ \\
\hline H9:Personal innovativeness & $0.046(0.494)$ & $0.380 *(2.366)$ \\
\hline H10:Task-Technology Fit & $0.485 * * *(4.489)$ & $0.150(1.180)$ \\
\hline H11:Essential Infrastructure & $0.106(1.149)$ & $-0.082(0.703)$ \\
\hline H12:Compatibility & $0.004(0.038)$ & $0.218 *(1.969)$ \\
\hline H13:Data Security & $0.115(1.096)$ & $0.122(0.946)$ \\
\hline
\end{tabular}

* Significance at $\alpha=0.05 .{ }^{* *}$ Significance at $\alpha=0.01$.

${ }^{* * *}$ Significance at $\alpha=0.001$.

\subsection{The impact of organizational factors on beliefs}

According to the result shown in the above table, our data analysis didn't show a significant impact of Management commitment on Perceived Usefulness and Perceived Ease of Use. Also, data analysis didn't support our hypothesis about the impact of Accessibility on Perceived Usefulness whereas it is revealed the non-significant impact of Accessibility on Perceived Ease of Use. One explanation for this unexpected finding is that maybe these factors manifest effects through the other factors such as user involvement in system development or communication channels. This casual relationship among the belief antecedents isn't addressed in this study.

Our data stated the weak influence of Rewardperformance relationship on Perceived Usefulness and Perceived Ease of Use. However, User involvement in system developing was positively and significantly (at $\alpha=0.01$ ) related to Perceived Usefulness (coefficient $=0.233$, $t$-value $=2.586$ ) and non-significant impact on Perceived Ease of Use. An explanation for this expected result is that involvement will lead to develop a better understanding of the new technology among users which improve system quality as well as increased usefulness perception.

Finally, the results provide support for the significant impact of Communication channels (at $\alpha=$ 0.01 ) on belief in terms of Perceived Usefulness (coefficient $=0.054, t$-value $=3.072)$. A possible explanation of this finding is that individuals use the communication channels for gathering information and specific knowledge about the new technology which can lead to reinforced belief of usefulness. But our hypothesis about the impact of Communication channels on belief in terms of Perceived Ease of Use didn't support.

\subsection{The impact of social factors on beliefs}

In the same manner, a significant relationship (at $\alpha=$ 0.01 ) was found between Subjective norms of department peers and informal groups and Perceived Usefulness (coefficient $=0.262, \mathrm{t}$-value $=2.759$ ). It could be implicated that a good relationship between end users, managers and peers in the organization could facilitate transmitting benefit of using a new technology to the end users and reinforce user belief toward system usefulness. But its impact on Perceived Ease of Use wasn't supported.

Quality of relationship with managers and peers didn't exhibit a significant influence on Perceived Usefulness but, it showed significant relationship (at $\alpha=0.01$ ) with Perceived Ease of Use (coefficient= 0.302 , t-value $=3.072$ ). A possible explanation for this finding is that good social exchanges in the organizational context can help individuals to exchange information about using the system easily. Thus, information sharing and knowledge exchanging 
will encourage and enhance user beliefs about system ease of use.

\subsection{The impact of individual factors on believe}

As shown in the PLS analysis results in Table 1, Selfefficacy didn't indicate a significant impact on Perceived Usefulness, however it showed a significant relationship (at $\alpha=0.05$ ) with Perceived Ease of Use (coefficient $=0.210$, $\mathrm{t}$-value $=2.309$ ). A plausible explanation for this finding is that high selfefficacy enhances individual's confidence of overcoming difficulties and obstacles which can lead to better judgment of their ability to engage in a new technology.

As expected, Personal innovativeness showed significant relationship (at $\alpha=0.05$ ) with Perceived Ease of Use (coefficient $=0.380$, t-value $=2.366$ ). Explanation for this significant effect is that individuals, who are earlier in adopting new things than others, will likely perceive a new technology user friendly, based on their previous experiences. This could lead to exhibiting positive beliefs about using a new technology. However, our data didn't show a significant relationship between Personal innovativeness and Perceived Usefulness.

\subsection{The impact of technological factors on beliefs}

As hypothesized, Task-Technology Fit had positive and significant effect (at $\alpha=0.001$ ) on Perceived Usefulness (coefficient $=0.485$, $\mathrm{t}$-value $=4.489$ ). This significant effect was expected since the system had been developed in-house and developers were quiet familiar with users' needs and requirements related to their tasks. This new technology helps users in their tasks and improves individual performance which finally affects user beliefs about system usefulness. But, Task-Technology Fit didn't exhibit strong effects on Perceived Ease of Use.

Also, the results didn't provide a significant support for the impact of Essential Infrastructure on Perceived Usefulness. Furthermore, it didn't support our hypothesis about the influence of this factor on Perceived Ease of Use.

As depicted in Table 1, Compatibility showed a significant effect (at $\alpha=0.05$ ) on Perceived Ease of Use (coefficient $=0.218, \quad t$-value $=1.969$ ). One plausible explanation for this significance link is that because of in-house system development, there was enough cognition about existing values, needs, and past experiences of users which leads to extending ease of use belief among them. Compatibility also didn't appear a significant impact on Perceived Usefulness.
Finally, Data security didn't exhibit a significant influence on beliefs in both terms of Perceived Ease of Use and Perceived Usefulness.

\section{Conclusion, limitations and future directions}

The objective of the present study is to focus on the factors influencing user beliefs associated with technology adoption. Considering that belief formation is a complex process which involves various factors, identification and examination of what factors drive users' beliefs toward a new technology is valuable.

The first contribution of this research in terms of theory has been the extension of prior researches by proposing a conceptual model which integrates four categories of external factors including: organizational, social, individual and technological factors, as the predictors of key beliefs in technology adoption.

Second, we tested the impact of these factors on beliefs about Ease of Use and Usefulness within the context of a Project Management Information System (PMIS). Third, despite previous research studies which had mostly focused on adoption of systems such as E-mail systems, word processing packages or spreadsheets which less contributes in the organization's core processes, the studied system applied in doing the company's core processes.

The findings of the present study highlighted the critical impact of user involvement in system developing on Perceived Usefulness. The link between user involvement and system using, has been shown in many previous studies e.g. King and Rodriguez $^{22}$; King and Rodriguez ${ }^{66}$; Lucas ${ }^{11}$ and Barudi et al. ${ }^{19}$.

Another important result is revealed by the significant impact of Communication channels, on Perceived Usefulness. This result is consistent with the findings of Agarwal and Prasad ${ }^{45}$ which highlighted the critical role of communication channels in determination of usefulness perceptions toward IT adoption.

In the social factor context, Subjective norms of department peers and informal groups indicated significant impact on Perceived Usefulness. It has found mixed support for impact of social influences on Perceived Usefulness in prior researches e.g., Karahanna et al. ${ }^{50}$. Hartwick and Barki ${ }^{67}$; Taylor and Todd $^{46}$; Karahanna et al. ${ }^{50}$; Venkatesh et al. ${ }^{68}$ have emphasized on the subjective norms as one of the important drivers of IS use. However, this relationship hasn't been supported in some others e.g. Lewis et al. ${ }^{35}$.

Meanwhile Quality of relationship with managers and peers showed a significant effect on Perceived 
Ease of Use. This finding emphasizes on the strength of informal social exchange in transmitting ease of use perception among employees which is consistent with the findings of Magni and Pennarola ${ }^{57}$.

With regard to individual factors, the results of this study indicated the key role of Self-efficacy in Perceived Ease of Use. This finding is consistent with the empirical results of Lewis et al. ${ }^{35}$. The fact that computer self-efficacy did not affect perceived usefulness is inconsistent with the empirical results of Compeau and Higgins ${ }^{69}$. It is possible that selfefficacy influences on perceived usefulness indirectly through Perceived Ease of Use.

Furthermore, our data confirmed the critical role of Personal innovativeness in Perceived Ease of Use. It confirms the findings of Agarwal and Prasad ${ }^{60}$ and Lewis et al. ${ }^{35}$.

Finally, in the technological factor perspective, our results suggested that Task-Technology Fit has a significant role in perceived usefulness. The strong linkage between Task-Technology Fit and performance has been demonstrated in some previous researches e.g. Goodhue and Thompson ${ }^{31}$. According to their findings, a new technology must be utilized and must be a good fit with the tasks it supports to enhance users' performance. Technology and users' tasks fitting implicate on meeting users needs in a given organization which finally leads to extending usefulness perception among users. Moreover, indirect effect of Task-Technology Fit on Perceived Usefulness through Perceived Ease of Use has showed by Dishaw and Strong ${ }^{61}$.

Likewise, our findings confirmed the significant influence of Compatibility on Perceived Ease of Use. This result is consistent with Al-Ghahtani and King ${ }^{70}$ findings which showed significant direct effect of compatibility on ease of use, as one of the most important antecedents of belief.

Generally, our results highlighted the significant impact of some of the external factors on users' beliefs in both terms of Perceived Ease of Use and Perceived Usefulness. Moreover, it's confirmed that the effects of all factors are not the same across the key beliefs in technology adoption. Some factors weren't so significant in user beliefs in perspective of system ease of use and usefulness. In this regard it is possible that these factors indicate their effects through the other beliefs which not considered in this study. It could be a good concern for further research and examination.

Our findings suggest that in total of four categories of external factors were introduced in this research, Individual factors were significant predictors of ease of use.

Prior to discussing the areas remain for future research, it's needed to acknowledge the study limitations. First, it must be emphasized that some of the respondents participated in this study had only one year of experience or less in employment and therefore couldn't be considered as real representative of system users. Moreover, once doing this research, it was two or three years past implementing the new system. Since the research model was proposed for the early stage of adoption, respondents had to remember their first perceptions toward the new system.

Although the present study considered a holistic view to the factors which influence on users' beliefs about system usefulness and ease of use but more work needs to be done to examine the effect of the other predictors of users' beliefs toward IT adoption. Furthermore, as mentioned earlier, indirect effect of some factors through the other factors rather than the direct effect could be considered as the subject of future researches. Testing the robustness of the research model across different set of companies and technologies could be the other area for future research, as well. Also, because of adoption can be occurred over time and in different stages, i.e., preadoption and post-adoption, examining the effect of the antecedents of beliefs in each stage could be useful and help managers to decide appropriately throughout the adoption process.

\section{References}

1. Hauge, C. Ayala and R. Conradi, Adoption of open source software in software-intensive organizations - A systematic literature review Review Article, Information and Software Technology, 52(11) (2010), pp.1133-1154.

2. D. Vavpotic and M. Bajec, An approach for concurrent evaluation of technical and social aspects of software development methodologies, Information and Software Technology, 51(2) (2009), pp.528-545.

3. C.M. Jackson, S. Chow and R.A. Leitch, Toward an understanding of the behavioral intention to use an information system, Decision Sciences 28 (2) (1997), pp.357-389.

4. D. Gefen and M. Keil, The impact of developer responsiveness on perceptions of usefulness and ease of use: an extension of the technology acceptance model, The DATA BASE for Advances in Information Systems 29(2) (1998), pp.35-49.

5. E. Karahanna, D.W. Straub and N.L. Chervany, Information technology adoption across time: a cross-sectional comparison of pre-adoption and 
post-adoption beliefs, MIS Quarterly 23 (2) (1999), pp.183-213.

6. F.D. Davis, R.P. Bagozzi and P.R. Warshaw, User acceptance of computer technology: a comparison of two theoretical models, Management science 35(8) (1989), pp.982-1003.

7. DeSanctis, G. Attitudes toward telecommuting: Implications for work-at-home programs, Information \& Management 7(3) (1984), pp.133139.

8. W. L. Fuerst and P. H. Cheney, Factors Affecting the Perceived Utilization of Computer- Based Decision Support Systems in the Oil Industry, Decision Sciences 13(4) (1982), pp.554-569.

9. M. J. Ginzberg, Early Diagnosis of MIS Implementation Failure: Promising Results and Unanswered Questions, Management Science 27(4) (1981), pp.459-478.

10. B. IVES, M. OLSON and J. BAROUDI, The Measurement of User Information Satisfaction, Communications of the ACM 26 (1983), pp.785793.

11. H.C. Lucas and Jr, Why information systems fail, Columbia University Press, New York (1975).

12. D. Robey, User attitudes and management information system use, Academy Of Management Information Journals 22(3) (1979), pp. 527-538.

13. R. L. Schultz and D. P. Slevin, Implementation and organizational validity: An empirical investigation. In R. L. Schultz \& D. P. Slevin (Eds.), Implementing operations research/management science, New York: American Elsevier (1975), pp.153-182.

14. A. SRINIVASAN, Alternative Measures of System Effectiveness: Associations and Implications, MIS Quarterly 9(3) (1985), pp.243253.

15. E.B. Swanson, Information Channel Disposition and Use, Decision Sciences 18(1) (1987), pp.131145.

16. I. Benbasat, A.S. Dexter and P. Todd, An Experimental Program Investigating ColorEnhanced and Graphical Information Presentation: An Integration of the Findings, Communications of the ACM 29(11) (1986), pp.1094-1105.

17. G.W. Dickson, G. Desanctis, and D.J. McBride, Understanding the Effectiveness of Computer Graphics for Decision Support: A Cumulative Experimental Approach, Communications of the ACM 29(1) (1986), pp.40-47.

18. T.W. Malone, Toward a theory of intrinsically motivating instruction, Cognitive Science 4 (1981), pp.333-369.

19. J.J. Baroudi, M.H. Olson and D. Ives, An empirical Study of the Impact of User Involvement on System Usage and Information Satisfaction, Communications of the ACM 29(3) (1986).

20. C.R. Fronz and D. Robey, Organizational Context, User Involvement and Usefulness of Information Systems, Decision Sciences 17(3) (1986), pp.329356.
21. M. Alavi, An assessment of the prototyping approach to information systems development, Communications of the ACM 27(6) (1984), pp.556-563.

22. W.R. King and J.I. Rodriguez, Participative design of strategic decision support systems: An empirical assessment, Manage.Sci 27(6) (1981), pp.717-726.

23. M. J. Ginzberg, A study of the implementation process. North-Holland/TIMS Studies in the Management Sciences. In press (1978).

24. I. Vertinsky, R.T. Barth and V. F. Mitchell, A study of OR/MS implementation as a social change process. In R. L. Schultz \& D. P. Slevin (Eds.), Implementing operations research/management science, New York: American Elsevier, (1975), pp. 253-270.

25. D. E. Zand and R. E. Sorensen, Theory of change and the effective use of management science, Administrative Science Quarterly 30 (4) (1975), pp.532-545.

26. Huber and P. George, Cognitive Style as a Basis for MIS and DSS Design: Much Ado About Nothing?, Management Science 29(5) (1983), pp.567-582.

27. M. Fishbein and I. Ajzen, Belief ,Attitude, Intention and Behavior: An Introduction to Theory and Research. Reading, Mass: Addison-Wesley (1975).

28. I. Azjen, From intentions to actions: A theory of planned behavior, in J. Kuhl, J. Beckmann (Eds.), Action Control: From Cognition to Behavior, Springer-Verlag, Berlin (1985), pp.11-39.

29. Rogers and M. Everett, Diffusion of Innovations, The Free Press, New York (1983).

30. F. D. Davis, A technology acceptance model for empirically testing new end-user information systems: Theory and results. Doctoral dissertation, Sloan School of Management, Massachusetts Institute of Technology (1986).

31. D. Goodhue and R. Thompson, Task-Technology Fit \& Individual Performance, MIS Quarterly (1995).

32. R. Agarwal and J. Prasad, Are individual differences germane to the acceptance of new information technologies?, Decision Sciences 30 (1999), pp.361-391.

33. V. Venkatesh and F. D. Davis, A Model of the Antecedents of Perceived Ease of Use: Development and Test, Decision Sciences 27(3) (1996), pp. 451-481.

34. R. Agarwal and E. Karahanna, Time Flies When You Are Having Fun: Cognitive Absorption and Beliefs About Information Technology Usage, MIS Quarterly 24(4) (2000), pp.665-694.

35. W. Lewis, R.Agarwal and V. Sambamurthy, Sources of influence on beliefs about information technology use: an empirical study of knowledge workers, MIS Quarterly 27(4) (2003), pp.657-678.

36. R. Agarwal, Individual acceptance of information technologies, in Zmud R.W. (edited by) "Framing the domains of IT management", Ohio, Pinnaflex (2000).

Published by Atlantis Press

Copyright: the authors 
37. D. Leonard-Barton and I. Deschamps, Managerial Influence in the Implementation of New Technology, Management Science 34(10) (1988), pp.1252-1265.

38. Zmud and W.Robert, An Examination of'PushPuU' Theory Applied to Process Innovation in Knowledge Work, Management Science 30(6) (1984), pp. 727-738.

39. A. D. Boynton, R. W. Zmud and G. C. Jacobs, The Influence of IT Management Practice on IT Use in Large Organizations, MIS Quarterly 18(3) (1994), pp.299-318.

40. R. Eisenberger, R. Huntington, S. Hutchison and D. Sowa, Perceived organizational support. Journal of Applied Psychology 71 (1986), pp.500507.

41. H. C. Lucas, Empirical Evidence for a Descriptive Model of Implementation. MIS Quarterly 2 (1978), pp.27-41.

42. L. W. Porter and E. E. Lawler, Managerial attitudes and performance, Homewood, 111.: Irwin-Dorsey (1968).R.

43. B. Ives and M.H. Olson, User involvement and MIS success: a review of research, Management science 30(5) (1984), pp.586-603.

44. S. Nilakanta and R.W. Scamell, The Effect of Information Sources and Communication Channels on the Diffusion of Innovation in a Data Base Development Environment, Management Science 36(1) (1990), pp.24-40.

45. R. Agarwal and J. Prasad, The antecedents and consequents of user perceptions in information technology adoption, Decision support system 22 (1998), pp.15-29.

46. S. Taylor and P. Todd, Understanding Information Technology Usage: A Test of Competing Models. Information Systems Research 6(2) (1995), pp.144-176.

47. R.L. Thompson, C.A. Higgins and J.M. Howell, Towards a Conceptual Model of Utilization, MIS Quarterly 15(1) (1991), pp.125-143.

48. A. Bandura, Social learning theory. Englewood Cliffs, NJ: Prentice-Hall (1977).

49. I. Azjen and M. Fishbein, Attitude-behaviour relations: A theoretical analysis and review of empirical research. Psychological Bulletin 84 (1977), pp.888-918.

50. E. Karahana and D.W. Straub, The psychological origins of perceived usefulness and ease-of-use, Information and Management 35 (1999), pp.237250.

51. K. Mathieson, Predicting User Intentions: Comparing the technology Acceptance Model with the Theory of Planned Behavior, Information Systems Research 2(3) (1991), pp.173-191.

52. R.M. Dienesh and R.C. Liden, Leader-member exchange model of leadership: a critique and further development. Academy of Management Review 11 (1986), pp.618-634.
53. R.T. Sparrowe and R.C. Liden, Process and structure in leader-member exchange, Academy of Management Review 22 (2) (1997), pp.522-552.

54. M.C. Bolino, W.H. Turnley and J.M. Bloodgood, Citizenship behaviour and the creation of social capital in organizations, Academy of Management Review 27 (4) (2002), pp.505-522.

55. D. Krackhardt, The strength of strong ties: the importance of philos in organizations. In R.G. Eccles and N. Nohria Eds., Networks and organizations: structure, form and action, Harvard Business School Press, MA (1992), pp.216-239.

56. C. R. Leana and H.J. Van Buren, Organizational social capital and employment practices. Academy of Management Review 24 (1999), pp.538-555.

57. M. Magni and F. Pennarola, Stand by me: the quality of intra-organizational relationships as antecedent of IT adoption (2003)

58. B. Hasan, Delineating the effects of general and system-specific computer self-efficacy beliefs on IS acceptance, Information and Management 43 (2006), pp.565-571.

59. T.C. Boyd and C.H. Mason, The Link between Attractiveness of "Extrabrand" Attributes and the Adoption of Innovations, Journal of the Academy of Marketing Science 27(3) (1999), pp.306-319.

60. Agarwal and J. Prasad, A conceptual and operational definition of personal innovativeness in the domain of information technology, Information Systems Research, 9(2) (1998).

61. M.T. Dishawa and D.M. Strong, Extending the technology acceptance model with tasktechnology fit constructs, Information \& Management 36(1) (1999), pp.9-21

62. J.W. Ross, C.M. Beath and D.L. Goodhue, Develop Long-Term Competitiveness through IT Assets, Sloan Management Review (1996), pp. 3142.

63. G. Moore and I. Benbasat, Development of an instrument to measures the perceptions of adopting an information technology innovation. Information systems research 2(3) (1999), pp.192-222.

64. W.W. Chin, The partial least squares approach for structurational equation modeling. Modern Methods for Business Research. Lawrence Erlbaum Associates (1998), pp.295-336.

65. W.W. Cotterman and J.A. (Eds.). Senn, Challenges and strategies for research in systems development. Wiley Series in Information Systems, Chichester (1992).

66. W.R. King and J.I. Rodriguez, Evaluating MIS, MIS Q 2(3) (1978), pp.43-52.

67. J. Hartwick and H. Barki, Explaining the Role of User Participation in IS Use, Management Science 40(4) (1994), pp. 440-465.

68. Venkatesh, Viswanath, Morris, G. Michael, Davis, B. Gordon and D. Fred, User acceptance of information technology: toward a unified view, MIS Quarterly 27(3) (2003).

69. D. R. Compeau and C. A. Higgins, Application of Social Cognitive Theory to Training for Computer 
Skills. Information Systems Research, 6 (2) (1995), pp.118-143.

70. S.S. AL-GAHTANI and M. KING, Attitudes, Satisfaction and usage: factors contributing to each in the acceptance of information technology,

Behaviour \& Information Technology, 18(4) (1999), pp. 277- 297.

\section{Appendix 1. Scales and Items}

\section{Management commitment and support (TOP/MID SUP)}

1. IOEC top managers/middle managers are committed to a vision of using PMIS in managing the projects.

2. IOEC top managers/middle managers are committed to supporting my efforts in using PMIS for managing projects.

3. IOEC top managers/middle managers are committed to financial supports for employing PMIS throughout IOEC.

4. IOEC top managers/middle managers strongly encourage the use of PMIS for managing projects.

5. IOEC top managers/middle managers will recognize my efforts in using PMIS.

6. The use of PMIS for managing projects is important to IOEC top managers/middle managers.

\section{Accessibility (ACCESS)}

1. During the PMIS development, the trial version was available to test.

2. There is always a help and support center to solve user problems in PMIS usage.

3. In the initial steps of PMIS usage, access to help and support center was easy.

4. During the implementation process, enough training was received.

\section{Reward-performance relationship (REW)}

1. In IOEC, there is a tight link between rewards and individual performance.

2. In IOEC, the quantity of rewards enhances in line with the performance improvement.

User involvement in system developing (INVOL)

1. I was permitted to comment about PMIS functionalities.

2. My idea is important for IOEC top managers.

3. During the primary steps of PMIS developments, my ideas about PMIS functionalities were considered.

\section{Communication channels (CHANNEL)}

1. The received information from various channels reduced my uncertainty about PMIS.

2. I received much information about PMIS by attending periodic meetings.

3. I received much information about PMIS from workshops.

4. I received much information about PMIS from experts outside the organization.

\section{Subjective norms of peers and informal groups (DEP SN) (INFORMAL SN)}

1. My departmental faculty colleagues think that using PMIS is valuable for managing the projects.

2. The opinions of my departmental faculty colleagues are important to me.

3. People in informal groups to which I belong think using PMIS is valuable for managing the projects.

4. The opinions of the people in informal groups to which I belong are important to me.

\section{Quality of relationship with managers and peers (REL)}

1. In IOEC, there is a good relationship (apart from formal reporting) between managers and employees.

2. In IOEC, I perceive myself as a member of the same social category.

3. In IOEC, employees have a high level of commitment to the organization.

\section{Self-efficacy (SELF)}

I could use a new software package...

1 .... if there was no one around to tell me what to do.

2. ... if I had never used a package like it before.

3 . ... if I had only the software manuals for reference.

4 . ... if I had seen someone else using it before trying it myself.

5 .... if someone else had helped me get started. 
6. ... if I had a lot of time to complete the job for which the software was provided.

Personal innovativeness (INNO)

1. I like to experiment with new things and ways for doing tasks.

2. I exploit every opportunity for learning and enhancing my skills.

3. As soon as I heard about a new information technology, I would look for ways to experiment with it.

4. Among my peers, I am usually the first to try out new information technologies.

\section{Essential infrastructure (INFRAS)}

1. The current PMIS hardware and infrastructure was designed appropriately.

2. There is a proper relationship between PMIS subsystems.

3. There are downtimes for PMIS.

\section{Task-Technology Fit (TTF)}

1. The PMIS data is up to date enough to do my job.

2. The PMIS data is in an appropriate level of details to provide my required reports.

3. PMIS provide enough information for me to do my job.

4. The PMIS outputs (such as reports and graphs) have a high quality.

\section{Compatibility (COMP)}

1. Using PMIS is compatible with all aspects of my work.

2. Using PMIS fits well into my work style.

3. PMIS is match with the other current systems.

4. PMIS is fit into the accepted organizational norms and values.

\section{Data privacy and security (SEC)}

1. I authorize to access to data that would be useful in doing my job.

2. There are rules and policies for checking data entered into PMIS.

3. In the case of web interactions, firewalls are considered to prevent unauthorized access.

\section{Perceived usefulness (PU)}

1. Using PMIS enables me to accomplish my tasks more quickly.

2. Using PMIS improves the quality of my work.

4. Using PMIS enhances my effectiveness.

5. Using PMIS improves my job performance.

6. Using PMIS gives me greater control over my job.

\section{Perceived ease of use (PEOU)}

1. My interaction with PMIS is clear and understandable.

2. Learning to operate a PWS is easy for me

2. Overall, I believe that it is easy to use PMIS.

4. Learning to use PMIS to support me in doing my task is easy for me.

5. Using a PMIS is often frustrating. 